\title{
News coverage and attitudes on immigration: Public and commercial television news
}

compared

\author{
Laura Jacobs $^{\text {a }}$ \& Cecil Meeusen ${ }^{b}$, Leen d'Haenens ${ }^{c}$ \\ University of Leuven
}

\author{
${ }^{a}$ Centre for Political Research, University of Leuven, \\ ${ }^{\mathrm{b}}$ Centre for Sociological Research, University of Leuven, \\ ${ }^{\mathrm{c}}$ Centre for Media Studies, University of Leuven
}

\section{Accepted for publication in European Journal of Communication}

\begin{abstract}
Public and commercial news follow distinct logics. We evaluate this duality in television news coverage on immigration. First, by means of a large-scale content analysis of Flemish television news $(\mathrm{N}=1,630)$, we investigate whether immigration coverage diverges between both broadcasters. Results show that, despite an overall negativity bias and relative homogeneity between the broadcasters, commercial news contains slightly more sensational and tabloid characteristics than public news. The latter promotes a more balanced view of immigration. These differences are stable over time. Second, using cross-sectional and panel data, we assess whether a preference for public versus commercial news is associated with an attitudinal gap in anti-immigrant attitudes. Findings demonstrate that individuals who prefer commercial news are more negative toward immigrants. We suggest that differences in news content may explain this attitudinal gap. In light of the debate around 'public value' offered by public service media across Europe, we tentatively conclude that public broadcasters have the potential to foster tolerance and provide balanced information by prioritizing a normative view over a market logic. The linkage between news coverage and the gap in attitudes between commercial and public news viewers warrants close investigation in the future.
\end{abstract}

Keywords: Immigration coverage, public service news, sensationalism, tabloidization, antiimmigrant attitudes

Corresponding author: Laura Jacobs, Centre for Political Research, University of Leuven, Parkstraat 45, box 3602, 3000 Leuven, Belgium. Email: laura.c.jacobs@kuleuven.be 


\section{News coverage and attitudes on immigration: Public and commercial television news compared}

The gradual shift to sensational and 'tabloid' characteristics in news coverage is welldocumented (Grabe, Zhou, \& Barnett, 2001; Slattery, Doremus, \& Marcus, 2001). From a democratic perspective, scholars have expressed concerns that this trend may lead to quality loss and eventually even undermine news media's traditional democratic function of informing citizens about social and political issues, such as immigration (Blumler \& Gurevitch, 1995; Iyengar, 2009). Generally, public opinion is quite intolerant toward immigrants and research has emphasized that negative stereotyping in news content can reinforce this hostility (Boomgaarden \& Vliegenthart, 2009; Schlueter \& Davidov, 2013).

Past studies have adopted a uni-dimensional approach when assessing news depictions and public opinion of immigrants, without differentiating between types of news broadcasters or specific news content. However, the 'dual effects hypothesis' (Aarts \& Semetko, 2003; Strömbäck \& Shehata, 2010) suggests that not all news media may yield similar effects. There is evidence that in Western Europe individuals differ in their civic attitudes according to their preference for public or commercial television news (Hooghe, 2002; Schmitt-Beck \& Wolsing, 2010). This observation has been attributed to the distinct logics and goals that both types of broadcasters adhere to, which would be reflected in their respective news programming content. Notwithstanding a striking variety as to funding, content provision and market prominence, public service broadcasting (PSB) is expected to fulfil a democratic role in society and therefore adopts a 'public logic', characterized by universal service, public value, quality, and diversity as key values, whereas the commercial news production process is dominated by a market-oriented logic characterized by audience maximization (d'Haenens, Sousa, \& Hultén, 2011; Thomass, Hallvard, \& d'Haenens, 2015). This duality of the European broadcasting 
landscape is explicitly recognized by EU institutions (see the Amsterdam Protocol, 1997), one consequence being that government subsidization is allowed on condition of sufficient transparency and proportionality between the funding provided and the services rendered to the different taste cultures of the audiences targeted. The specific way both broadcasters cover immigration news may reflect these different logics (Van den Bulck \& Broos, 2011). Commercial news is expected to stress more sensational news features (e.g. emotions, conflict) and to contain more 'tabloid' characteristics (e.g. soft news topics) than public television news (Esser, 1999; Hendriks Vettehen, Zhou, Kleemans, d'Haenens, \& Lin, 2012). In line with its public interest goal, public television news is anticipated to depict immigrants more positively by providing background and context, and by emphasizing the added value of immigration for society (Van den Bulck \& Broos, 2011).

To the best of our knowledge, the dual-effects hypothesis has never been systematically tested for immigration news coverage and attitudes. In the past years, several public broadcasters in Western Europe have systematically monitored their output as to depicted diversity of identities. Results showed that success in terms of improved quality of immigrant depictions in news content can only be achieved if sustained diversity policy initiatives (reflected in target and quota figures) are put in place and lived by. If findings show that a distinct approach in news content emerges -with immigration coverage on public news being less relegated to specific secluded spheres of society linked to crime and deviance (d'Haenens \& Mattelart, 2011)-, this would suggest that efforts by public broadcasters, following a public logic, are successful. Especially in the current era of austerity where the role and fate of public broadcasters are heavily debated, this question gains even more relevance.

The goal of this study is twofold. First, and most importantly, we assess whether public and commercial television newscasts diverge in immigration coverage. Second, we examine whether a gap in anti-immigrant attitudes between public and commercial television viewers 
exists. We systematically compare specific news content on immigration between commercial and public television news in Flanders (the Dutch-speaking region of Belgium) and analyze public opinion data. We apply insights from the debate on news quality and journalism, such as trends toward sensationalism and tabloidization to immigration news coverage.

\section{A dual effects hypothesis: public and commercial news compared}

\section{Different logics, different content}

Western Europe has a long-standing tradition of public service television (Bardoel \& d'Haenens, 2008). Despite substantial cross-national differences in the modalities of PSB, several common features can be distinguished (Syvertsen, 2003). Generally, PSB can be considered as 'a major pillar of the democratic process' (Iyengar, 2009). Public broadcasters are usually at least partly state-funded, liberating them from commercial pressures and dependence upon advertising revenues. In return for this privilege, they are mandated to deliver public services while adhering to democratic principles and values (Holtz-Bacha \& Norris, 2001). Providing citizens with balanced information, educating on societal issues and stimulating pluralistic values are core functions (Rogers, O’Boyle, Preston, \& Fehr, 2014). By lack of financial state support, commercial broadcasters do not have similar obligations to serve the public interest and are more market-oriented, increasing their dependence on profit and audience maximization, hence having less incentives to report on immigration in a balanced manner (Rogers et al., 2014). Moreover, media theories suggest that due to competition, commercial broadcasters are more susceptible to report sensational news stories and disseminate 'tabloid' stories, such as crime and 'soft' news, stressing news values like conflict and negativity (Hendriks Vettehen, Nuijten \& Beentjes, 2005). An increased tendency toward sensationalism in immigration coverage has indeed been documented especially in commercial news (Benson, 2002). 
We suggest that this distinct logic of both broadcasters is reflected in news content on immigration. More particularly, we rely on three key concepts of political communication sensationalism, tabloidization, and reflection of democratic values by balanced and objective reporting- to identify how news content between public and commercial broadcasters diverges in a way which could contribute to an attitudinal gap between its viewers. We only focus on actual news content and do not consider differences in formal news features. Moreover, we restrict ourselves to 'sensational' or 'tabloid' aspects applicable to immigration news coverage.

Sensationalism is a vague, multi-layered and hotly debated concept. Studies often relate sensationalism to a dramatic discourse by defining it as "emotionally arousing features in the news' (Grabe et al., 2001; Pantti, 2010; Uribe \& Gunter, 2007). In terms of content, news topics such as crime, conflict, terrorism, disaster, human interest and showbiz are considered 'sensational' because they stir emotions, often at the expense of a more rational discourse (Slattery et al., 2001). Generally, sensationalism has a negative connotation, as it is associated with declining news quality, potentially undermining news's democratic function (Blumler \& Gurevitch, 1995). There is indeed evidence that commercialized news environments contain more sensational elements (Hendriks Vettehen et al., 2005; Slattery et al., 2001). Especially conflict tends to be a more common ingredient on commercial television news compared to public news because conflict is considered attractive, straightforward, accessible, and easy to follow (Lowry, Nio, \& Leitner, 2003). We hypothesize that:

H1: Commercial television news on immigration contains more elements of sensationalism than public television news.

A second potential difference between public and commercial news -somewhat related to sensationalism- refers to the degree of 'tabloidization'. There is no uniform definition for 
tabloidization, but it generally denotes a process toward an increased presence of 'tabloid characteristics' in the news (Esser, 1999). In terms of news content, tabloidization corresponds with a shift in news values from more serious, 'hard' news topics, such as politics and economics, to more trivial, 'soft' news topics, such as crime and human interest (Esser, 1999). Hard news covers issues considered to be socially relevant, informative and mainly directed at public affairs reporting, whereas soft news tends to be less important or urgent and mainly has an entertainment-value (Baum \& Jamison, 2008). Tabloid news generally reduces the complexity of issues, prefers a simplified reading of events, lacks in-depth coverage, and focuses on personalized narratives to enhance feelings of closeness and identification (McLachlan \& Golding, 2000; Sparks \& Tulloch, 2000). The overall concern is that tabloidization would undermine journalistic quality (Grabe et al., 2001). By disseminating less hard news, citizens would not be adequately informed, hence lacking the necessary tools to formulate a well-balanced opinion. In 'Is Anyone Responsible', Iyengar (1991) showed that individuals exposed to episodic news, highlighting exemplars and covering news from a personalized angle, in contrast to exposure to thematic news stressing the broader social context, were more likely to attribute responsibility to individuals, disregarding societal factors. The increase of tabloidization is largely attributed to news' increasing market-orientation (Blumler \& Gurevitch, 1995; Dahlgren \& Sparks, 1992). Past studies have indeed found that commercial news incorporates more tabloid characteristics than public service media (Bek, 2004; Norris, 2000). We therefore hypothesize that:

H2: Commercial television news on immigration contains more elements of 'tabloidization' than public television news.

A third potential difference between both broadcasters is the commitment to offer a balanced representation of immigration. One function of public broadcasters' democratic role 
is to promote a tolerant climate for various minority groups in society and to reflect this diversity in their programming (Rogers et al., 2014). In some regions, e.g. the UK, the Netherlands and Flanders, the stimulation of on-screen ethnic diversity and balanced minority portrayals are explicit responsibilities of PSB (Van den Bulck \& Broos, 2011). Some public broadcasters maintain concrete target figures to increase minority visibility and thus fulfil a crucial role in creating and sustaining pluralist democratic societies in Europe (Iyengar, 2009). This suggests that public broadcasters will make an effort to equally report on immigrants, limiting disproportionate references to problems and negative consequences. Due to their larger freedom, the lack of directives, and their market-oriented logic, commercial broadcasters have less incentives, other than audience-driven ones, to reflect diversity and to depict minorities in a balanced way, rendering these newscasts more prone to patterns of stereotyping (Van den Bulck \& Broos, 2011). We hypothesize that:

H3: Public television news on immigrants contains more positive elements than commercial television news.

\section{Different content, different attitudes}

Abundant evidence emphasizes the role of news content of immigration, in terms of stereotyping, tone and framing, in the formation of anti-immigrant attitudes among majority groups (Boomgaarden \& Vliegenthart, 2009; Schemer, 2014). However, news content on immigration may greatly diverge between public and commercial broadcasters due to their distinct logic. The 'dual effects hypothesis' (Aarts \& Semetko, 2003; Strömbäck \& Shehata, 2010) suggests that PSB, due to their public service duty and outspoken information function, are generally more effective in fostering civic attitudes such as political knowledge, interest and social capital, than commercial broadcasters (Holtz-Bacha \& Norris, 2001; Hooghe, 2002; Schmitt-Beck \& Wolsing, 2010). Although previous research established a close relationship 
between news content and public opinion on immigrants, differences between types of news broadcasters remain underexplored in this regard.

More specifically, public and commercial broadcasters are expected to diverge in the use of sensational and tabloid elements in news on immigration, which could result in an attitudinal gap. As mentioned, sensational and tabloid styles in news reporting may undermine democratic attitudes (Blumler \& Gurevitch, 1995), as typically these types of news content are narrowly focused on conflict, simplification, and lack in-depth-coverage (Dahlgren \& Sparks, 1992). By contrast, more balanced and nuanced news can be expected to foster tolerance toward immigration. Therefore, we assess whether broadcaster preference is related to attitudes toward immigration. We hypothesize that:

H4: Individuals who watch public television news have more positive attitudes toward immigration than individuals who watch commercial television news.

When conducting media effects research it is crucial to ascertain that conclusions are not an artefact of self-selection (Aarts \& Semetko, 2003). There is always a possibility that observed differences in attitudes are not due to media socialization processes, but rather the result of individuals selecting news media perceived to be in line with their predispositions. Moreover, public opinion may steer media content as well (Zhou \& Moy, 2007). In essence, these questions can be traced back to the primordial question of causality. The ideal strategy to alleviate this pitfall would be to adopt an experimental design, which permits randomization and manipulation in a controlled setting. Unfortunately, we currently do not have experimental data, but we can rely on panel data in a cross-lagged design, and control for alternative mechanisms like media consumption (Schuck, Vliegenthart, \& de Vreese, 2015). Although this approach is not entirely conclusive because of its inability to rule out influences of 
environmental changes or to establish definite causality, it does present the second best strategy, which makes a tentative conclusion possible.

\section{The Flemish television market}

Flanders, with its dual broadcasting system and strong public broadcaster co-existing with commercial players, presents an excellent case study. In their typology of media systems, Hallin and Mancini (2004) classify Flanders as a democratic corporatist model: early development of mass media, high professionalism, press freedom, and the presence of a strong public broadcaster. The two main players on the television market are the public broadcaster VRT and the commercial broadcaster VTM. Their flagship newscasts attract the large majority of market shares every evening. In 2014, 'Het Journaal' on VRT reached a market share of $52.6 \%$, while 'Het Nieuws' on VTM reached $42.8 \%$. No other Flemish newscasts attract similar numbers of viewers (CIM TV, 2014). The publicly funded public broadcaster VRT is commissioned by the Flemish government to fulfil several requirements with regard to diversity in programming, staff and audience. In 2003, VRT adopted the Charter of Diversity, institutionalizing its commitment to reflect diversity on and off screen and to promote tolerance in society (Van den Bulck \& Broos, 2011). As such, VRT explicitly adopts an inclusive and pluralistic strategy as part of its general aim to serve the public interest. The commercial broadcaster VTM does not have similar obligations.

\section{Data and methods}

\section{Content analysis}

Data. Data for the content analysis were collected via the Electronic News Archive (ENA). Since 2003, the ENA collects, codes and analyzes every prime-time newscast of the two main broadcasters. For every news item, a team of professional coders provided a general 
description (usually the text read by the news anchor), several keywords and the main topics. Inter-coder reliability scores are satisfactory (De Smedt, Wouters, \& De Swert, 2013).

Sample. To select all television news coverage on immigration, a string of search terms was developed. Using this search string, all news items from 2003 until 2013 containing a reference to immigration or ethnic and religious minority actors and issues in either the overall description or keywords were selected $(n=6,074)^{1}$. Only domestic news was included as we agree with Ter Wal and colleagues (2005) that the operationalization of an ethnic minority or immigrant is highly context-specific. A subsample of 1,630 news items (27\%) was coded into more detail according to the studies' purposes.

Coding and Inter-coder reliability. The coding was conducted by a team of trained researchers. During the training, coding guidelines were explained in detail. Several examples were collectively coded. Subsequently, coders were assigned to code test items to apply the training materials. Later, these codings were compared to identify difficulties. In case of ambiguity, the team watched the whole news story and jointly decided on the coding. Intercoder reliability was evaluated by double-coding a subset of the sample and was above the minimum value .67 with an average Krippendorff's alpha value of .77 and average percent agreement of $90.0 \% .^{2}$

Variables. The unit of analysis was the news item. The news content variables were operationalized as indicators of the three main explanatory mechanisms: sensationalism, tabloidization and balanced representations of immigration (Table 1).

Sensationalism. Two indicators of sensationalism were coded: the presence of negative verbalized emotions (fear, anger) and references to conflict. First, negative verbalized emotions were taken up because sensationalism has been described as an increase in emotional appeals (Uribe \& Gunter, 2007). Anger and fear were selected as basic intergroup emotions (Mackie, Smith, \& Ray, 2008). In the codebook, both emotions were described by means of several 
equivalents (e.g. for anger: 'angry', 'fury', 'rage'; for fear: 'afraid', 'fear', 'terror'). The presence of negative verbalized emotions was scored if any of these equivalents were identified in the news item (Hendriks Vettehen et al., 2005).

Second, conflict is also deemed a key characteristic of sensational news. Conflict is the expression of negativity as a news value, easily lends itself to emotional appeals, and has the potential to grasp the audiences' attention (Slattery et al., 2001). The presence of conflict was operationalized as conflictual interactions between the immigrant and majority group in the news item. First, it was coded whether there was any interaction at all, and then whether the nature of the interaction was cooperative, conflictual or both. Conflictual interactions could range from subtle expressions (verbal disputes) to more obvious conflict (physical aggression).

Tabloidization. For tabloidization, there were two indicators: episodic versus thematic framing, and references to soft versus hard news. First, episodic and thematic frames were coded because they refer to personalization elements, a key 'tabloid' characteristic (Iyengar, 1991). In thematic framing attention is paid to the overall background of the issue. Episodic framing depicts concrete and personalized events to illustrate issues. Using this definition, coders indicated whether news items were framed primarily episodically or thematically. Another key aspect of 'tabloidization' is the shift from a focus on 'hard' to 'soft' news. All news items were on immigration, but also contained links with other topics. As the soft vs. hard news distinction is still subject to criticism, we adopted common elements from most definitions (Baum \& Jamison, 2008). Soft news items have a high-entertainment value and report on less socially relevant issues, whereas hard news is more focused on public affairs and informing citizens. Stories referring to politics (negotiations, political institutions, policy, elections), the economy (welfare, economic growth, finance and monetary policy), and social policy, such as labour (labour policy, unemployment) and rights (human rights, racism) were 
coded as 'hard news'. 'Soft' news stories were coded when news contained references to crime and justice (criminal acts, trials) and terrorism (terrorist acts, radicalisation).

Balanced representation of immigration. This mechanism is inspired by the idea that PSB will adhere more to democratic principles, reflect ethnic diversity and promote tolerance by disseminating balanced depictions of immigration. As indicators, we included the tone of news on immigration, references to problems, and references to positive or negative consequences of immigration. The tone or general 'valence' adds an affective component to the message. It was coded using the following question: 'Overall, would you say the news item has a positive, negative, mixed or neutral tone?' (Van Klingeren, Boomgaarden, Vliegenthart, \& De Vreese, 2014). For example, a news item stating that 'the balance of integration efforts for immigrants is successful', was coded as 'positive'; an item reporting on an immigrant involved in crime was coded as 'negative'. References to problems and its cause were coded when respectively a news item reported on a problem and when immigrants were portrayed as cause of this problem. Finally, positive consequences of immigration could, for instance, refer to enrichment for culture or society, economic benefits (filling shortage occupation, increase of welfare) or commitment to respecting human rights. Negative consequences could, for instance, refer to safety issues (increase in crime or terrorism), cultural and religious contrasts and tensions, or economic conflicts (competition on labour market, increased welfare expenditure, illegal work and abuse of social benefits).

\section{Survey analysis}

Data. The survey data stem from two waves of the Belgian Election Panel Survey 20092014 (Dassonneville, Falk Pedersen, Grieb, \& Hooghe, 2014). In 2009, a geographically stratified sample of 4,831 adult Belgians was randomly selected from the National Register. Fieldwork resulted in 2,331 completed face-to-face interviews (48.3\%). In 2014, the original 
2009 sample was updated and 4,488 addresses could be recovered. After three reminders, 1,542 (34.4\%) valid self-administered questionnaires were returned. For the purpose of this study, only respondents from the Flemish subsample who indicated that they had watched either public or commercial news were included in the final sample. For the cross-sectional analyses we can rely on a sample of $\mathrm{N}=1,099$ in 2009 and $\mathrm{N}=709$ in 2014. For the panel analyses, we rely on a sample of $\mathrm{N}=439$, i.e. respondents who indicated to watch public or commercial news in 2009 and 2014.

Measures. Preference for public or commercial news was measured by asking respondents which television newscast they had watched most often during the last two weeks. In 2009, this was administered with a closed-ended question and respondents had to select from a list of four broadcasters (33.6\% commercial news, $66.4 \%$ public news). In 2014, television news preference was registered with an open question that was coded by the authors afterwards (26.0\% commercial news, $74.0 \%$ public news). Among the respondents participating in both waves, only $10 \%$ switched news broadcaster between 2009 and 2014 (5\% from public to commercial news and 5\% from commercial to public news). Broadcaster preference seems to be very stable.

Anti-immigrant attitudes were assessed with different indicators. In 2009, two prejudice proxies were used: (1) Attitudes toward asylum seekers ('Belgium should close its borders for asylum seekers' - five-point Likert scale disagree-agree), (2) Attitudes toward immigration ('Immigration contributes to the welfare of our country' - five-point Likert scale disagreeagree). In 2014, following items were available: (1) Attitudes toward asylum seekers ('Belgium should close its borders for asylum seekers' - five-point Likert scale disagree-agree), (2) Economic threat due to immigration ('In general, it is good for the Belgian economy that people from different countries come to live here' - five-point Likert scale disagree-agree - reversed scaled), (3) Cultural threat due to immigration ('In general, the cultural life in Belgium is 
undermined because people of different countries come and live here' - five-point Likert scale disagree-agree), (4) Positive feelings toward immigrants (Feeling thermometer 0-100 scale, higher values indicating more positive feelings), (5) Opinion about ethnic diversity ('Belgium has become a better place because of the presence of people from different countries' - fivepoint Likert scale disagree-agree). Unfortunately, most items were only measured at one point in time, restricting us to cross-sectional analyses. Attitudes toward asylum seekers were measured at both time points, allowing a panel design. Because one-item measures are not ideal and we have more than three items in 2014, we also constructed a scale based on all 2014 items (one-dimensional, Cronbach's Alpha $=.784)$.

Importantly, to avoid spurious effects, we controlled for gender ( $0=$ Male, $1=$ Female), education level (1='no degree', 6='university degree'), age, religious denomination ( $0=$ ='nonreligious', 1='religious'), economic position ('how would you describe the economic situation of your family during the last year', 1='it deteriorated strongly', 5='it improved strongly'), left-right ideology $\left(0={ }^{\prime}\right.$ left', $10=$ 'right'), political interest $(0=$ 'not at all interested', $10=$ 'extremely interested'), frequency of television news consumption ( $1=$ 'never', $6=$ 'daily'), and frequency of other news media consumption (newspaper, news websites, radio news, 1='never', 6='daily'). All control variables were identically measured in 2009 and 2014.

\section{Findings}

\section{Content analysis}

First, we analyze whether immigration news coverage diverges between public and commercial broadcasters (Table 1). In terms of sensationalism (Figure 1), negative verbalized emotions are common on both public and commercial news: approximately a quarter of all news stories contain references to anger and fear. Commercial television news on immigrants appeals more often to negative emotions such as anger $(+8 \%)$ and fear $(+7 \%)$ than public 
television news. References to conflict also present common features of news stories, but commercial television news contains more conflictual interactions than public news $(+8 \%)$. Hypothesis 1 is thus confirmed: commercial television news reports on immigration contain slightly more sensational elements than public news.

\section{[Figure 1]}

Figure 2 compares public and commercial television in terms of tabloidization. With regard to framing, news stories on immigration are less often covered from a general, thematic perspective, and more from a personalized, episodic perspective. Commercial television news more often adopts an episodic perspective $(+10 \%)$ than public news, which more often offers a thematic perspective $(+9 \%)$. Assessing which news topics occur in conjunction with immigration reveals that overall most news items are related to issues on crime and justice, followed by politics, terrorism and economy. 'Soft news' topics, e.g. crime, thus often find their way to immigration coverage. Again, commercial news more often contains 'soft news' topics, whereas public newscasts contain more 'hard news' topics. However, this does not apply to all news topics equally. Regarding soft news topics, commercial news reports more often on crime and justice $(+11 \%)$, but there is no difference for terrorism. Regarding hard news topics, public news reports more often on politics $(+8 \%)$, labour $(+4 \%)$ and rights $(+4 \%)$, but there is no difference for economic issues. It seems that PSB focuses more on serious news, offering a diverse supply of news topics, whereas commercial news more narrowly focuses on crime and justice. We can confirm hypothesis 2 stating that commercial news has slightly more tabloid characteristics than public news.

[Figure 2] 
Figure 3 presents differences between public and commercial television news content in terms of a balanced representation of immigration. Overall, television news is heavily negatively biased: negative tone, references to negative consequences and problems are widespread. Again, public and commercial newscasts somewhat diverge. Public news more often has a positive tone $(+4 \%)$ and less often a negative tone $(-9 \%)$ than commercial news, although positive news is scarce overall (5.9\%). Public and commercial news report evenly on problems, but immigrants are less often portrayed as cause of a problem on public news $(-6 \%)$ than on commercial news. Next, PSB more often mentions positive consequences $(+6 \%)$ and less often negative consequences $(-9 \%)$ of immigration than commercial television news. We conclude that immigration is approached in a slightly more balanced manner on public television news than on commercial news, confirming hypothesis $3 .^{3}$

\section{[Figure 3]}

\section{[Table 1]}

\section{Survey analysis}

To provide a tentative assessment of whether individuals who tend to watch public news instead of commercial news have more positive attitudes toward immigrants, we performed a range of cross-sectional (2009 wave and 2014 wave) and cross-lagged regression analyses (panel 2009-2014). Whereas cross-sectional analyses are correlational and do not provide any indication of causality, cross-lagged models make use of the time order in the panel data to address this issue.

Table 2 presents the results of the cross-sectional regressions, which clearly confirm hypothesis 4: individuals preferring public television news are more tolerant toward the 
entrance of asylum seekers and immigration, perceive less cultural threat and hold more positive feelings toward immigration than individuals preferring commercial television news. The $R^{2}$ contributions of adding the news broadcaster are relatively small, however, with the highest contribution for positive feelings toward immigrants in 2009. Only with regard to economic threat and positive attitudes toward ethnic diversity no significant difference between public and commercial news could be observed, suggesting that television content contributes less to economic and ethnic plurality motivations of anti-immigrant prejudice. For economic threat, one's own economic situation is more important than news consumption. Frequency of television news consumption is not significantly related to attitudes toward immigration, except for a small relation with economic threat. Frequency of other media consumption has no significant relations whatsoever. Finally, regarding the control variables, individuals with high political interest, high education and a left-wing orientation report less prejudice.

\section{[Table 2]}

Next, we performed a cross-lagged model. In a cross-lagged model the 2014 variables are regressed on the 2009 variables. Cross-lagged coefficients represent the effect of $X$ in 2009 on $\mathrm{Y}$ in 2014, while controlling for the stability of X and Y between 2009 and 2014 (i.e. autoregressive coefficients). As only attitudes toward asylum seekers were measured at two time points, we propose a cross-lagged model (Figure 4) and assess whether the preference for public vs. commercial news in 2009 defines attitudes in 2014, whether attitudes in 2009 define the preference for public vs. commercial news in 2014 , or whether the causal mechanism is a combination of both pathways.

[Figure 4] 
Table 3 displays the results of the cross-lagged model. The autoregressive parameters show high stability of preference for public vs. commercial news and attitudes toward asylum seekers between 2009 and 2014: individuals do not tend to change news consumption habits or attitudes easily. The cross-lagged effect of preference for public news vs. commercial news in 2009 on attitudes in 2014 was significant while the effect of attitudes in 2009 on preference for public vs. commercial news in 2014 was not. This provides tentative evidence for a causal mechanism from news consumption to prejudice, and not the other way round. ${ }^{4}$

\section{[Table 3]}

\section{Discussion}

This study contributes to the broader academic debate on the alleged decline in news quality by assessing sensational and tabloid styles of news coverage as potential sources of anti-immigrant attitudes. We expected differences in goal attainment of public and commercial broadcasters to reflect in news content, possibly resulting in an attitude gap between individuals preferring commercial over public news.

First, content analysis confirms that there are particular elements in news content which reflect the different logic of both broadcasters, although overall differences remain limited. Public news more often stresses positivity and positive consequences of immigration for society whereas commercial news contains slightly more sensational and tabloid characteristics: references to negative emotions and conflict are more prevalent, news is more personalized, contains less in-depth coverage and background, instead focusing on soft news topics (e.g. crime). Second, we found provisional evidence that individuals preferring public news are more positive toward immigration than commercial news viewers, even when controlling for audience characteristics. Furthermore, cross-lagged analysis provided tentative proof that the causal mechanism runs from watching news to attitudes, and not vice versa. 
These findings correspond to literature assessing the potential effects of television news exposure on civic attitudes (Aarts \& Semetko, 2003; Hooghe, 2002; Schmitt-Beck \& Wolsing, 2010; Strömbäck \& Shehata, 2010). As such, this study corroborates prior conclusions that public news contains specific content elements, which may foster a civic mind-set like political knowledge, interest, participation and social capital. We expanded these insights with the preliminary suggestion that differences in news content on immigration between public and commercial television possibly shape public opinion on this topic too.

Still, nuance is in order. Differences between public and commercial news, while significant and stable, remain fairly limited, and overall both broadcasters follow similar patterns in news coverage. Public television news also contained considerable sensational and tabloid news features, revealing the relative homogeneity of both broadcasters. News content on immigration consistently encompasses negative elements and pays only little attention to positive exemplars. The main conclusion simply seems to be that this negativity bias holds less for public television news. An explanation may be that the dual broadcasting system in Flanders with a strong PBS and commercial players allows for a balance between both types of broadcasters, possibly also inspired by a process of convergence (Syvertsen, 2003).

However, the provisional support for a 'dual effects' hypothesis cautiously implies that -even in the current era of commercialization, diversification and austerity- public broadcasters may still have an important duty to fulfil in an increasingly multicultural society. Whereas commercial broadcasters seem to address television viewers as clients or consumers, public television news seems to address them primarily as citizens. The role of public broadcasters in stimulating civic attitudes and setting social norms, such as tolerance toward immigration, should thus not be simply disregarded. It highlights that sustained policy initiatives explicitly taken to promote tolerance, such as the VRT Charter of Diversity seem to yield results and pay off in the longer run, although there is clearly considerable scope for 
improvement. The presence of a strong and viable public broadcaster offers opportunities in best practices to deal with cultural diversity by prioritizing a normative vision over a market logic, which may fall short in responding to the democratic needs of diverse societies (Awad, 2008). As is observed by Rogers et al. (2014) small differences may prove to be significant in the future as public broadcasters, more than commercial broadcasters, seem to be increasingly aware of the normative challenges of a multicultural society. Possibly current initiatives aimed at increasing diversity are somewhat underexplored, and it may be useful to start a reflection process on how broadcasters could or should cope with this new situation.

Several limitations should be acknowledged. We emphasized differences between public and commercial broadcasters in actual television news content. However, also news format features, such as the use of images or audio-visual cues, may contain sensational or tabloid elements, which should be addressed by future studies (Kleemans, Van Cauwenberge, d'Haenens \& Hendriks Vettehen, 2008). Second, data limitations made it impossible to integrate news content indicators in the survey analysis, restricting us to a two-step approach. First, we systematically compared news content between both broadcasters, while in a second step -adopting news content as potential explanation- we evaluated differences in attitudes between public and commercial television viewers. Hence, our suggestion of news content as explanatory mechanism for the attitudinal gap between public and commercial television news viewers remains tentative and warrants further investigation. Further research should replicate these findings in other contexts and with other prejudice measures, adopting an experimental approach to rule out the concerns about environmental developments and self-selection.

Notwithstanding these limitations, this study is one of the first to systematically address the hypothesized difference between public and commercial news in the case of immigration coverage. We conclude that the distinct logic of both broadcaster types may be an important factor in understanding the relation between exposure to news media content and prejudice. 


\section{References}

Aarts, K., \& Semetko, H. A. (2003). The divided electorate: Media use and political involvement. The Journal of Politics, 65(3), 759-784.

Awad, I. (2008). Cultural diversity in the news media: A democratic or commercial need? Javnost-The public, 16(4), 55-72.

Bardoel, J. L. H., \& d'Haenens, L. (2008). Converging PSB Policies in Western Europe: The Netherlands and Flanders Compared. Journal of Global Mass Communication, 1(3/4), 190-209.

Baum, M. A., \& Jamison, A. S. (2008). The Oprah Effect: How Soft News Helps Inattentive Citizens Vote Consistently. The Journal of Politics, 68(4), 946-959.

Bek, M. G. (2004). Research note: Tabloidization of news media: An analysis of television news in Turkey. European Journal of Communication, 19(3), 371-386.

Benson, R. (2002). The political/literary model of French journalism: Change and continuity in immigration news coverage, 1973-1991. Journal of European Area Studies, 10(1), 4970.

Blumler, J. G., \& Gurevitch, M. (1995). The crisis of public communication. London, Routledge.

Boomgaarden, H. G., \& Vliegenthart, R. (2009). How news content influences antiimmigration attitudes: Germany, 1993-2005. European Journal of Political Research, $48(4), 516-542$.

CEC. (1997). Protocol on the System of Public Broadcasting in the Member States Attached to the Treaty of Amsterdam, C 340/109.

d'Haenens, L., \& Mattelart, T. (2011). Media and ethnic minorities. In W. Trappel, L. Meier, L. d'Haenens, \& J. Steemers (Eds.), Media in Europe today. Bristol: Intellect.

d'Haenens, L., Sousa, H., \& Hultén, O. (2011). From public broadcasting to public service 
media. In J. Trappel, W. Meier, L. D’Haenens, \& J. Steemers (Eds.), Media in Europe today. Bristol: Intellect.

Dahlgren, P., \& Sparks, C. (1992). Journalism and popular culture. London: Sage Publications.

Dassonneville, R., Falk Pedersen, E., Grieb, A., \& Hooghe, M. (2014). Belgian Election Panel 2009-2014: Technical Report. Leuven.

De Smedt, J., Wouters, R., \& De Swert, K. (2013). Inter-coder reliability in the TV News Archive. A report on coding issues, countries and actors in Belgian television news. Antwerp: Steunpunt Media.

Esser, F. (1999). ‘Tabloidization’ of news: A comparative analysis of Anglo-American and German press journalism. European Journal of Communication, 14(3), 291-324.

Grabe, M. E., Zhou, S., \& Barnett, B. (2001). Explicating sensationalism in television news: content and the bells and whistles of form. Journal of Broadcasting \& Electronic Media, 45(4), 635-655.

Hallin, D. C., \& Mancini, P. (2004). Comparing media systems. Three models of media and politics. New York: Cambridge University Press.

Hendriks Vettehen, P., Nuijten, K., \& Beentjes, J. (2005). News in an age of competition: The case of sensationalism in Dutch television news, 1995-2001. Journal of Broadcasting \& Electronic Media, 49(3), 282-295.

Hendriks Vettehen, P., Zhou, S., Kleemans, M., d'Haenens, L., \& Lin, T. (2012). Competetive pressure and arousing television news: A cross-cultural study. Asian Journal of Communication, 22(2), 179-196.

Holtz-Bacha, C., \& Norris, P. (2001). "To entertain, inform, and educate": Still the role of public television. Political Communication, 18(2), 123-140.

Hooghe, M. (2002). Watching television and civic engagement: Disentangling the effects of 
time, programs, and stations. Harvard International Journal of Press/Politics, 7(2), 84104.

Iyengar, S. (1991). Is anyone responsible. Chicago: The University of Chicago Press.

Iyengar, S. (2009). Absence of diversity: Market-based journalism, vote-seeking candidates, and racial cues in media programming. In H. Markus \& P. Moya (Eds.), Race and Culture in the 21st Century. NY: W. W. Norton.

Kleemans, M., Van Cauwenberge, A., d'Haenens, L., \& Hendriks Vettehen, P. (2008). Op zoek naar verklaringen voor sensatie in het nieuws: een vergelijking tussen Nederlandse, Vlaamse, Waalse en Franse televisiejournaals. [Looking for explanations for sensation in the news: a comparison between Dutch, Flemish, Walloon and French television newscasts]. Tijdschrift Voor Communicatiewetenschap, 36(4), 301-319.

Lowry, D. T., Nio, T. C. J., \& Leitner, D. W. (2003). Setting the public fear agenda: A longitudinal analysis of network TV crime reporting, public perceptions of crime, and FBI crime statistics. Journal of Communication, 53(1), 61-73.

Mackie, D. M., Smith, E. R., \& Ray, D. G. (2008). Intergroup emotions and intergroup relations. Social and Personality Psychology Compass, 2(5), 1866-1880.

McLachlan, S., \& Golding, P. (2000). Tabloidization in the British press: A quantitative investigation into changes in British newspapers 1952-1997. In C. Sparks \& J. Tulloch (Eds.), Tabloid Tales: Global Debates over Media Standards. Lanham, MD, Boulder, CO, New York and Oxford: Rowman and Littlefield.

Norris, P. (2000). A virtuous circle. Political communications in postindustrial societies. Cambridge: Cambridge University Press.

Pantti, M. (2010). The value of emotion: An examination of television journalists' notions on emotionality. European Journal of Communication, 25(2), 168-181.

Rogers, J., O’Boyle, N., Preston, P., \& Fehr, F. (2014). The significance of small differences: 
Cultural diversity and broadcasting in Ireland. European Journal of Communication, 29(4), 399-415.

Schemer, C. (2014). Media effects on racial attitudes: Evidence from a three-wave panel survey in a political campaign. International Journal of Public Opinion Research, 26(4), 531542.

Schlueter, E., \& Davidov, E. (2013). Contextual sources of perceived group threat: Negative immigration-related news teports, immigrant group size and their interaction, Spain 19962007. European Sociological Review, 29(2), 179-191.

Schmitt-Beck, R., \& Wolsing, A. (2010). European TV environments and citizens ' social trust: Evidence from multilevel analyses. Communications, 35(4), 461-483.

Schuck, A. R. T., Vliegenthart, R., \& de Vreese, C. H. (2015). Matching theory and data: Why combining media content with survey data matters. British Journal of Political Science, $1-9$.

Slattery, K., Doremus, M., \& Marcus, L. (2001). Shifts in public affairs reporting on the network evening news: A move toward the sensational. Journal of Broadcasting \& Electronic Media, 45(2), 290-302.

Sparks, C., \& Tulloch, J. (2000). Tabloid tales: Global debates over media standards. (C. Sparks \& J. Tulloch, Eds.). Lanham, MD, Boulder, CO, New York and Oxford: Rowman and Littlefield.

Strömbäck, J., \& Shehata, A. (2010). Media malaise or a virtuous circle? Exploring the causal relationships between news media exposure, political news attention and political interest. European Journal of Political Research, 49(5), 575-597.

Syvertsen, T. (2003). Challenges to public television in the era of convergence and commercialization. Television \& New Media, 4(2), 155-175.

Ter Wal, J., d'Haenens, L., \& Koeman, J. (2005). (Re)presentation of ethnicity in EU and Dutch 
domestic news: A quantitative analysis. Media, Culture \& Society, 27(6), 937-950.

Thomass, B., Hallvard, M., \& D’Haenens, L. (2015). Renewing public service media remit. In J. Trappel, J. Steemers, \& B. Thomass (Eds.), European media in crisis: Values, risks and policies. London: Routledge.

Uribe, R., \& Gunter, B. (2007). Are "sensational" news stories more likely to trigger viewers' emotions than non-sensational news stories?: A content analysis of British TV news. European Journal of Criminology, 22(2), 207-228.

Van den Bulck, H., \& Broos, D. (2011). Can a charter make the difference in ethnic minority reporting? A comparative content and production analysis of two Flemish television newscast. Communications, 36(2), 195-216.

Van Klingeren, M., Boomgaarden, H. G., Vliegenthart, R., \& De Vreese, C. H. (2014). Real world is not enough: The media as an additional source of negative attitudes toward immigration, comparing Denmark and the Netherlands. European Sociological Review, 1-16.

Zhou, Y., \& Moy, P. (2007). Parsing framing processes: The interplay between online public 


\section{Funding}

The first author gratefully acknowledge financial support from the European Research Council [ERC Advanced Grant number 295920].

\section{Acknowledgments}

The second author wishes to thank the Research Foundation Flanders (FWO) for the PhD fellowship, which made it possible to contribute to this article. We also thank Julie De Smedt for the practical support while retrieving the news items, and the anonymous reviewers for their constructive and insightful criticism.

\section{Notes:}

${ }^{1}$ The key words referred to immigrants and immigration-related issues, and to ethnic minorities by selecting mentions of nationality, ethnicity or minority group status, references to integration and minority issues (e.g. racism, religion and integration). Our content analysis thus includes news stories on immigrants and ethnic minorities, whereas our survey data (cf. infra) mainly focus on anti-immigrant attitudes. While not fully comparable, usually anti-immigrant attitudes are directed toward ethnic minorities, and correlations between attitudes toward immigrants and ethnic minorities are high. For reasons of readability, we refer to immigrants, but it should be noted that the content analysis also includes news on ethnic minorities. Full search string is available upon request.

${ }^{2}$ Inter-coder reliability per variable was as follows. For negative verbalized emotions: $\alpha=.81$, 91.2\% percentage agreement (PA). For conflictual interactions: $\alpha=.87,92.3 \%$ PA. For the type of frame (episodic vs. thematic): $\alpha=.70,86.2 \%$ PA. For news topic (hard vs. soft) $\alpha=.78,84.3 \%$ PA. For negative consequences, $\alpha=.75,92.3 \%$ PA. For positive consequences, $\alpha=.86,98.8 \%$ 
PA. For references to problems, $\alpha=.71,93.9 \%$ PA. For cause of problems, $\alpha=.79,87.7 \%$ PA. For tone, $\alpha=.69,87.6 \%$ PA.

${ }^{3}$ Data inspection reveals that differences between public and commercial news, although small, are stable over time.

${ }^{4}$ Because the cross-lagged parameter 'Attitude 2009 $\rightarrow$ Public news 2014' is based on a probit regression and the cross-lagged parameter 'Public news 2009 $\rightarrow$ Attitude 2014' on a linear regression, the size of both parameters cannot directly be compared (not the same link function). We performed the same cross-lagged model without taking the categorical nature of preference for public vs. commercial news into account and specified it as a continuous indicator. This way, the cross-lagged effects are both based on a linear regression and could be compared. These results indicated that the cross-lagged effect 'Public news 2009 $\rightarrow$ Attitude 2014' was significantly larger ( $p$-value<.001) than the cross-lagged effect 'Attitude 2009 $\rightarrow$ Public news 2014'. 
Figure 1. Sensationalism in television news content on ethnic minorities and immigration.

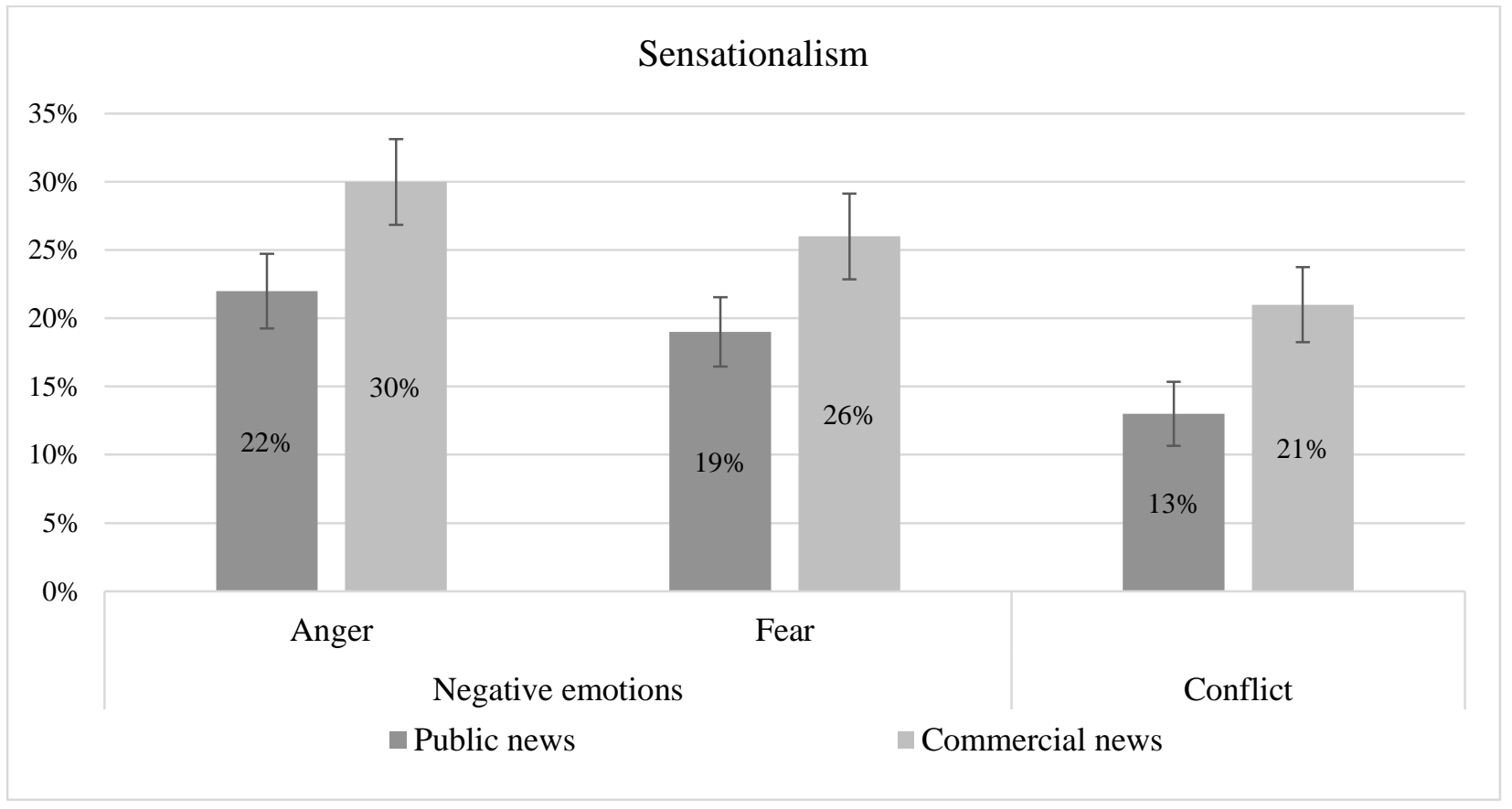

Figure 2. Tabloidization in television news content on ethnic minorities and immigration.

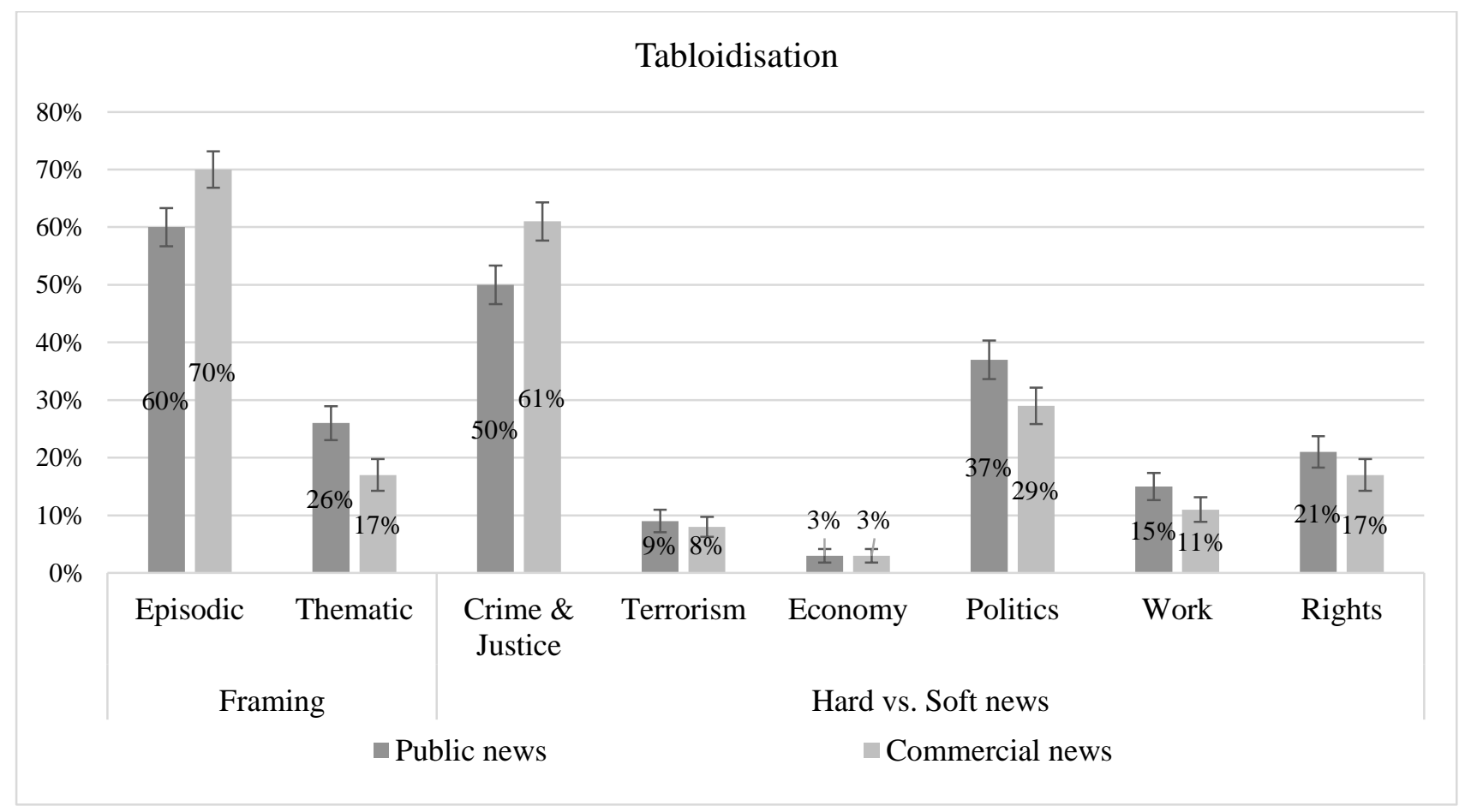


Figure 3. Balanced representation of ethnic diversity and immigration in television news content on immigration.

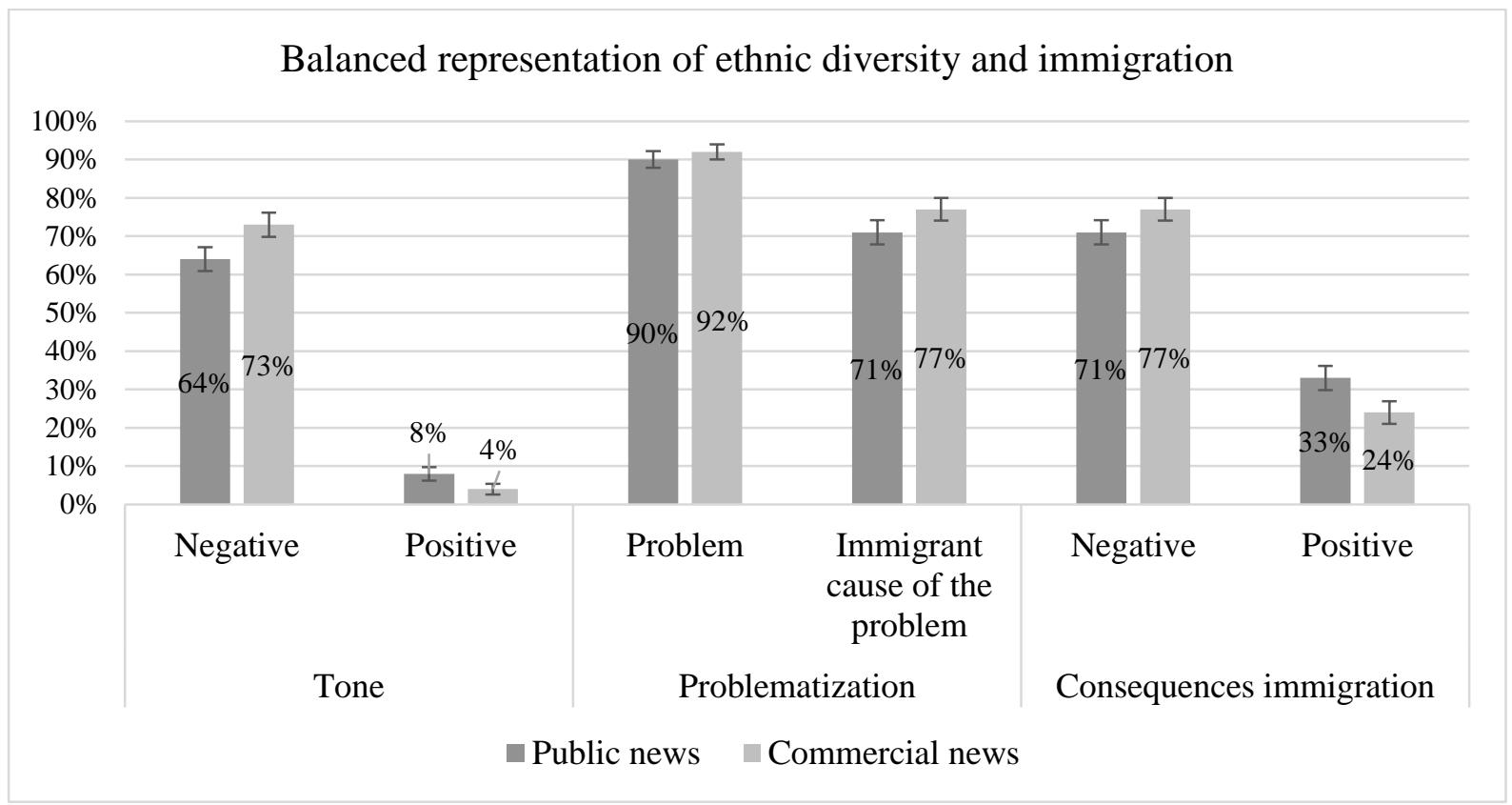


Table 1. Summary of content analysis indicators and results. ${ }^{3}$

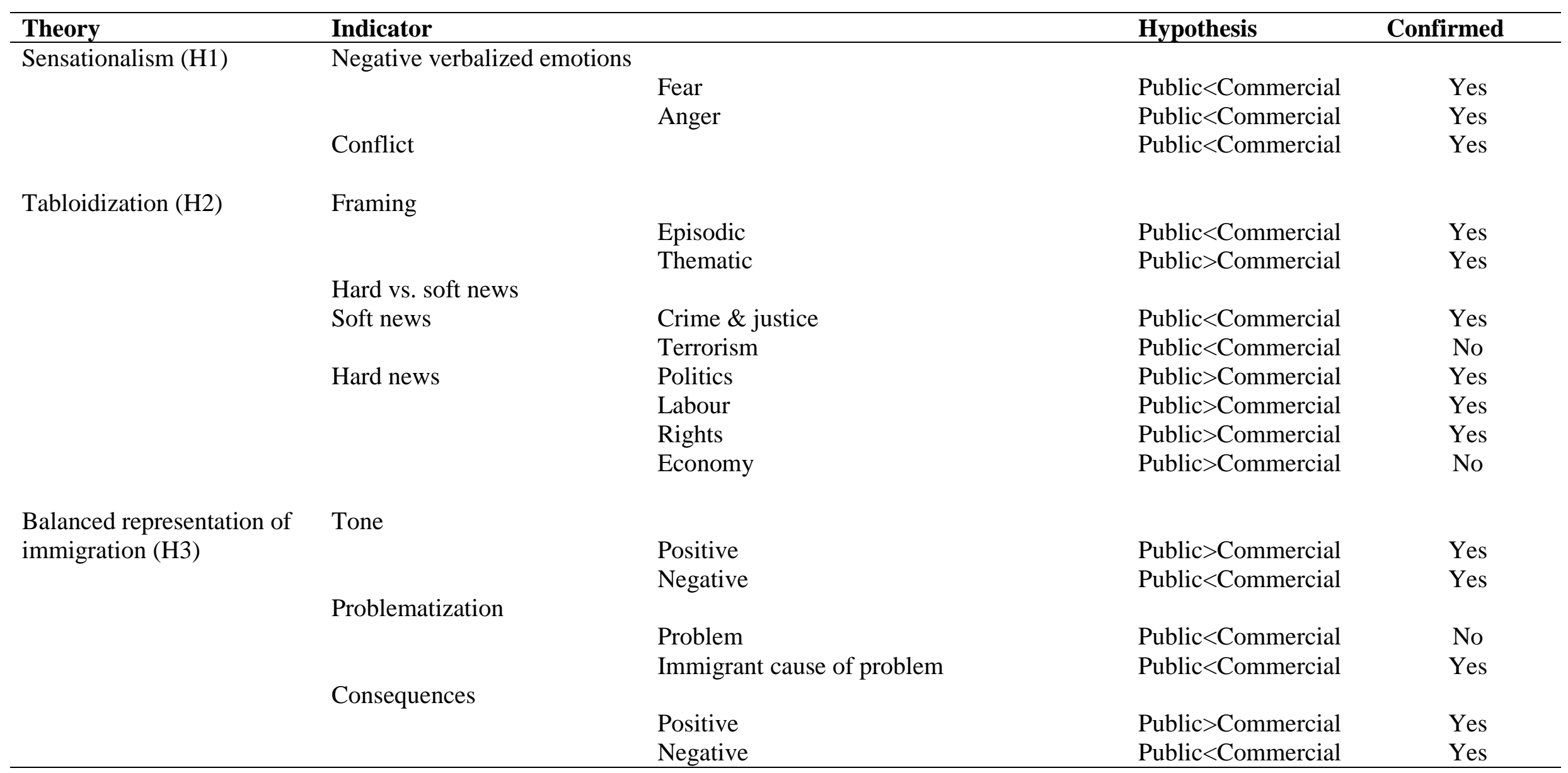


Table 2. Public versus commercial news and attitudes toward immigration.

\begin{tabular}{|c|c|c|c|c|c|c|c|c|}
\hline & 2009 & & 2014 & & & & & \\
\hline & $\begin{array}{c}\text { 'Belgium } \\
\text { should close } \\
\text { its borders for } \\
\text { asylum } \\
\text { seekers' }\end{array}$ & $\begin{array}{l}\text { 'Immigration } \\
\text { contributes to } \\
\text { the welfare of } \\
\text { our country' }\end{array}$ & $\begin{array}{c}\text { 'Belgium } \\
\text { should close its } \\
\text { borders for } \\
\text { asylum seekers' }\end{array}$ & $\begin{array}{l}\text { 'Economic threat } \\
\text { of immigration' }\end{array}$ & $\begin{array}{c}\text { 'Cultural } \\
\text { threat of } \\
\text { immigration' }\end{array}$ & $\begin{array}{l}\text { 'Positive } \\
\text { feelings toward } \\
\text { immigrants' }\end{array}$ & $\begin{array}{l}\text { 'Ethnic } \\
\text { diversity is a } \\
\text { good thing' }\end{array}$ & $\begin{array}{c}\text { Scale of } 2014 \\
\text { items (high values } \\
=\text { tolerance) }\end{array}$ \\
\hline & $\beta$ & $\beta$ & $\beta$ & $\beta$ & $\beta$ & $\beta$ & $\beta$ & $\beta$ \\
\hline $\begin{array}{l}\text { Public tv news } \quad(0= \\
\text { Commercial news })\end{array}$ & $-.133 * * *$ & $.094 * *$ & $-.120 * *$ & -.026 & $-.105 * *$ & $.174 * * *$ & -.023 & $.166 * *$ \\
\hline Gender $(0=$ Male $)$ & .023 & .019 & -.017 & .000 & $-.071^{\mathrm{a}}$ & .042 & -.028 & .024 \\
\hline Education level & $-.243 * * *$ & $.159 * * *$ & $-.191 * * *$ & $-.120 * *$ & $-.210 * * *$ & $.126^{* *}$ & .049 & $.202 * * *$ \\
\hline Age in years & .045 & -.057 & .021 & -.057 & $.087^{\mathrm{a}}$ & $-.103 *$ & .014 & -.027 \\
\hline Economic position & -.016 & .041 & -.040 & $-.134 * * *$ & -.031 & $.114 * *$ & $.089 *$ & $.104 * *$ \\
\hline $\begin{array}{l}\text { Religious denomination } \\
(0=\mathrm{No})\end{array}$ & .033 & -.025 & .052 & -.024 & .044 & -.030 & -.055 & -.039 \\
\hline Left-right ideology & $.182 * * *$ & $-.142 * * *$ & $.227 * * *$ & $.188^{* * *}$ & $.182 * * *$ & $-.192 * * *$ & $-.298 * * *$ & $-.295 * * *$ \\
\hline $\begin{array}{l}\text { Frequency tv news } \\
\text { consumption }\end{array}$ & .045 & -.054 & $.073^{\mathrm{a}}$ & $.101 *$ & -.003 & -.021 & -.031 & -.008 \\
\hline $\begin{array}{l}\text { Frequency other media } \\
\text { consumption }\end{array}$ & -.022 & .001 & -.003 & .018 & .003 & .000 & -.060 & -.065 \\
\hline Political interest & $-.126 * * *$ & $.158 * * *$ & $-.256 * * *$ & $-.235 * * *$ & $-.175^{* * *}$ & $.197 * * *$ & $.194 * * *$ & $.262 * * *$ \\
\hline $\mathrm{R}^{2}$ with public tv news & .198 & .127 & .224 & .133 & .182 & .206 & .127 & .279 \\
\hline $\mathrm{R}^{2}$ without public tv news & .183 & .119 & .211 & .132 & .172 & .180 & .127 & .267 \\
\hline$\Delta \mathrm{R}^{2}$ & .015 & .008 & .013 & .001 & .010 & .026 & .000 & .012 \\
\hline $\mathrm{N}$ & 1,024 & 1,020 & 627 & 626 & 626 & 587 & 626 & 580 \\
\hline Range & $1-5$ & $1-5$ & $1-5$ & $1-5$ & $1-5$ & $0-100$ & $1-5$ & $-2.04-2.88$ \\
\hline Mean (SD) & $3.07(1.31)$ & $2.86(1.13)$ & $3.60(1.23)$ & $3.41(1.03)$ & $3.07(1.24)$ & $44.20(25.10)$ & $2.47(1.10)$ & $0(1)$ \\
\hline
\end{tabular}


Figure 4. Cross-lagged model of relation between news broadcaster and attitudes toward asylum seekers

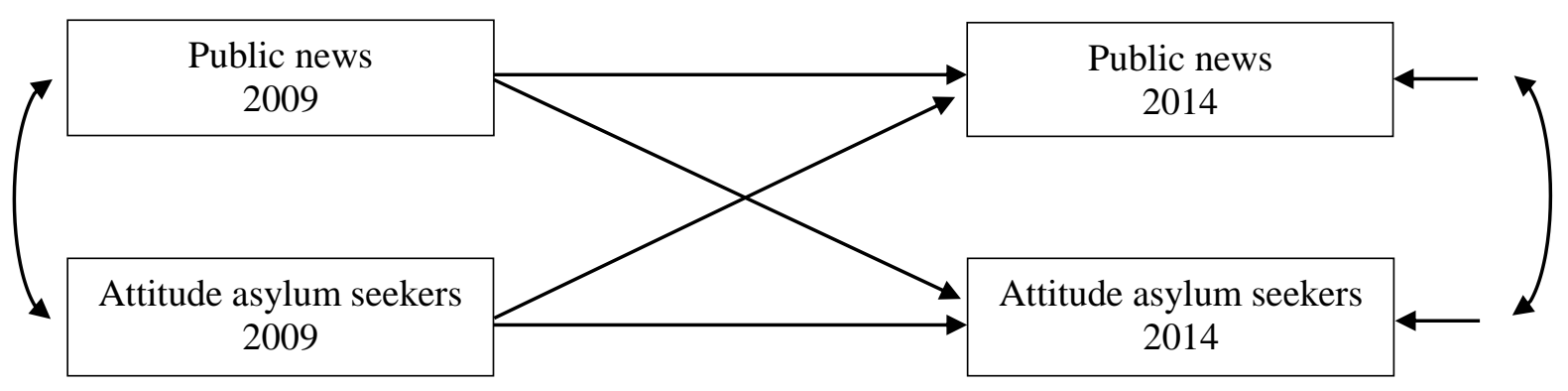

Table 3. Estimates of cross-lagged model of relation between news broadcaster and attitudes toward asylum seekers.

\begin{tabular}{|c|c|c|}
\hline & No control variables & $\begin{array}{l}\text { Including control } \\
\text { variables }^{\mathrm{a}}\end{array}$ \\
\hline & $\beta$ & B \\
\hline \multicolumn{3}{|l|}{ Autoregressive } \\
\hline Public news $2009 \rightarrow$ Public news 2014 & $.673 * * *$ & $.639 * * *$ \\
\hline Attitude $2009 \rightarrow$ Attitude 2014 & $.495 * * *$ & $.449 * * *$ \\
\hline \multicolumn{3}{|l|}{ Cross-lagged } \\
\hline Public news $2009 \rightarrow$ Attitude 2014 & $-.161 * * *$ & $-.137 * * *$ \\
\hline Attitude $2009 \rightarrow$ Public news 2014 & -.077 & -.065 \\
\hline $\mathrm{N}$ & 437 & 433 \\
\hline
\end{tabular}

${ }^{a}$ Controlled for time-invariant indicators age, education and gender.

Note. WLSMV estimation in Mplus 7.3. Entries 'Public news 2009 $\rightarrow$ Public news 2014' and 'Attitude $2009 \rightarrow$ Public news 2014' are standardized probit regression parameters. Entries 'Attitude 2009 $\rightarrow$ Attitude 2014' and 'Public news 2009 $\rightarrow$ Attitude 2014' are standardized linear regression parameters. Listwise deletion. Sign: *p $<.05 ; * * \mathrm{p}<.01 ; * * * \mathrm{p}<.0$ 